\title{
Less frequent and more intense rainfall along the coast of the Gulf of Guinea in West and Central Africa (1981-2014)
}

\author{
Adeline Bichet* ${ }^{*}$ Arona Diedhiou \\ University Grenoble Alpes, Institute for Geo-Sciences and Environment, 38058 Grenoble, France
}

\begin{abstract}
Since the 1990s, rainfall has been reported to increase over the Gulf of Guinea. In light of the devastating floods that have occurred since then over the coastal areas of this region, this study aims to better characterize the recent trends in precipitation there. We used the Climate Hazards Group InfraRed Precipitation with Station (CHIRPS) product, a new observational rainfall dataset that covers the period 1981-2014 at high resolution and daily time steps. During the first rainy season (April-June), we find that the lack of significant trend observed in mean precipitation hides a trend towards less frequent but more intense rainfall along the coast of the Gulf of Guinea, which is expected to increase the likelihood of flooding and droughts, and fits with the recent increase in devastating floods. Over the north however (between $7^{\circ}$ and $12.5^{\circ} \mathrm{N}$ ), rainfall has become more frequent and less intense, which is expected to decrease the likelihood of flooding and droughts. During the second rainy season (September-November), we find that the clear increase in mean precipitation observed between $5^{\circ}$ and $12.5^{\circ} \mathrm{N}$ results from an increase in precipitation intensity and frequency, while over southern Cameroon, the decrease in mean precipitation hides a trend towards less frequent but more intense rainfall. In both seasons, the average duration of wet spells has greatly decreased along the coast, in favor of more numerous and more intense isolated wet days.
\end{abstract}

KEY WORDS: CHIRPS - Dry spell - Guinea Coast - Precipitation intensity - Wet spell · AMMA-CATCH $\cdot$ Trend $\cdot$ Flood

\section{INTRODUCTION}

With a cumulative annual rainfall of about $1500 \mathrm{~mm}$ $\mathrm{yr}^{-1}$, the Gulf of Guinea represents the wettest region of West Africa. Although globally wet, the region receives most of its rainfall over the western coasts (from Liberia to Guinea and from Nigeria to Gabon), as a result of the orientation of the coastline and inland mountains. Being governed by the West African monsoon, rainfall is not evenly distributed across the year. A first rainy season occurs during the months of April, May, and June (AMJ) when the monsoon is moving northward, and a second rainy season occurs during the months of September, October, and November (SON) when the monsoon is moving southward. The rest of the year is relatively dry.

${ }^{*}$ Corresponding author:

adeline.bichet@univ-grenoble-alpes.fr
Over the 20th century, precipitation in this area also showed strong interannual variability (Diatta \& Fink 2014) and a weaker decadal variability (Sanogo et al. 2015). Although less pronounced than in the Sahel, the latter follows a similar evolution: The dry decades of 1920-1949 precede the wet decades of 1950-1969 (the 2 wettest decades in the 20th century) and the very dry decades of 1970-1989. Since the 1990s, precipitation has been reported to increase again (e.g. Nicholson 2000, Ofori-Sarpong \& Annor 2001), and this period has been qualified as a 'rainfall recovery' period (Sanogo et al. 2015).

In this region, such variations in precipitation greatly affect society, in particular though necessary adaptations to cropping strategies and shortfalls in hydropower provisions in drier years. Associated

(C) The authors 2018. Open Access under Creative Commons by Attribution Licence. Use, distribution and reproduction are unrestricted. Authors and original publication must be credited.

Publisher: Inter-Research · www.int-res.com 
changes in the frequency and intensity of extreme events such as floods also constitute an important threat for the region, as they are often associated with human and infrastructure damages, as well as perturbations in the water and electricity management. Between 1998 and 2016, recurrent flood cases (number of floods in brackets) were also reported by the Office for the Coordination of Humanitarian Affairs (OCHA) and the Emergency Events Database (EM-DAT) along the coastal areas of the Gulf of Guinea, where the main cities and capitals are located, with high damage to the infrastructure and the resident populations: Nigeria (23), Benin (9), Togo (5), Ghana (11), Côte d'Ivoire (4), Liberia (3), and Sierra Leone (5).

Despite such conditions, the current context of global climate change, and the rapid growth in demography and development of this region, very little is known about the 'rainfall recovery,' and the associated changes in hydro-climate characteristics are still unclear and poorly documented. This is partly due to the lack of continuous, high-resolution ground observations (e.g. no data are available over Liberia, Sierra Leone, and northern Ivory Coast, and there is poor coverage of the Global Telecommunication System of the World Meteorological Organization data over Guinea, Ghana, and Nigeria). In contrast to the Sahel region, for which long-term observations with the recent international program African Monsoon Multidisciplinary Analysis (AMMA) have improved the understanding of changes in precipitation extremes (Panthou et al. 2018), no field campaign has been dedicated to the understanding of climate variability on the coast of Guinea since the Convection Profonde Tropicale 1981 (COPT81, northern part of Ivory Coast in Korhogo, see Sommeria \& Testud 1984). Therefore, open key questions remain when dealing with the nature of climate change in this subregion (Roux 1988, Redelsperger et al. 2006, Christensen et al. 2007). In addition, precipitation over this region is generally poorly simulated by climate models; global climate models (GCMs) poorly reproduce the convective cloud systems in this subregion, and in particular the low layer convective systems (Hannack et al. 2017). This bias is usually explained by the difficulty to properly reproduce the processes of the atmospheric boundary layer above the ocean and the continental surface as well as the land-ocean flux gradients that drive the triggering and variability of the cloud systems. Whereas regional climate models (RCMs) may be part of the solution thanks to their better representation of land surface characteristics, they are also weak in representing surface-atmosphere interac- tions in these coastal areas where the dynamics of the atmosphere and the convection are partly controlled by the influence of the land-ocean surface meridional gradient (Diallo et al. 2013, Klutse et al. 2016).

Therefore in this study, we propose to take advantage of a high-resolution, gridded, daily rainfall dataset (Climate Hazards Group InfraRed Precipitation with Station, CHIRPS; see Funk et al. 2015) that covers Africa over the period 1981-2014, to characterize the trends in rainfall distribution over the Gulf of Guinea for the past $35 \mathrm{yr}$. After describing the dataset and the methods in Section 2, a brief evaluation of some of the trends discussed in this study is performed against rain gauges in Section 3.1. Trends in precipitation and precipitation intensity are investigated in Section 3.2, and trends in the distribution of wet and dry events are analyzed in Section 3.3. Discussion and conclusions are presented in Section 4.

\section{DATASET AND METHODS}

\subsection{Dataset}

We used the CHIRPS rainfall dataset (Funk et al. 2015), which is designed for monitoring global environmental change over the land surfaces. CHIRPS combines infrared satellite data with ground-based observations and corresponds to a gridded, quasiglobal $\left(50^{\circ} \mathrm{S}\right.$ to $\left.50^{\circ} \mathrm{N}\right)$, high resolution $\left(0.05^{\circ}\right)$, daily rainfall dataset that covers the time period 19812014. CHIRPS was validated using various rainfall observation data, and the results indicate good performance for drought monitoring. Annual trends over Africa also fall in general agreement with other observational data (Maidment et al. 2015, Bichet \& Diedhiou 2018).

Although a comprehensive validation of the CHIRPS dataset is beyond the scope of this study, we nevertheless perform a brief assessment of some of the trends discussed in this study, comparing them with the corresponding trends from near-surface daily rain gauges. As in Bichet \& Diedhiou (2018), 18 stations were selected from the updated BADOPLU database described by Panthou et al. (2012), based on the availability of data over the period of interest (1981-2014) and the homogeneous distribution of the stations across the region. Fig. 1 shows the locations of these 18 stations: Cap Skirring $\left(12.39^{\circ} \mathrm{N}, 16.75^{\circ} \mathrm{W}\right)$, Kangaba $\left(11.93^{\circ} \mathrm{N}, 8.39^{\circ} \mathrm{W}\right)$, Sikasso $\left(11.35^{\circ} \mathrm{N}\right.$, $\left.5.67^{\circ} \mathrm{W}\right)$, Bole $\left(9.03^{\circ} \mathrm{N}, 2.48^{\circ} \mathrm{W}\right)$, Accra Kotoka International Airport $\left(5.6^{\circ} \mathrm{N}, 0.17^{\circ} \mathrm{W}\right)$, Cotonou Airport $\left(6.35^{\circ} \mathrm{N}, 2.38^{\circ} \mathrm{E}\right)$, Lome Airport $\left(6.15^{\circ} \mathrm{N}, 1.25^{\circ} \mathrm{E}\right)$, 


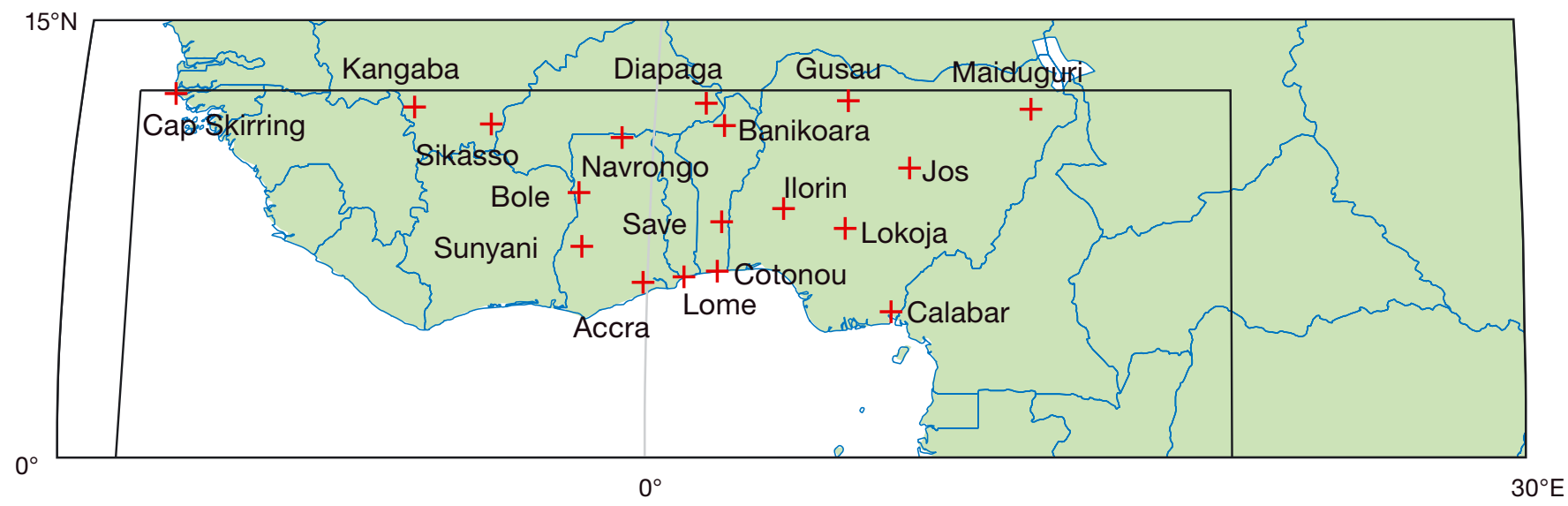

Fig. 1. West Africa, showing the 'Gulf of Guinea' region considered in this study $\left(18^{\circ} \mathrm{W}-20^{\circ} \mathrm{E}, 0^{\circ}-12.5^{\circ} \mathrm{N}\right)$, outlined by the black rectangle. The locations of the 18 daily rain gauge stations used for comparison are represented by red crosses

Save $\left(8.02^{\circ} \mathrm{N}, 2.48^{\circ} \mathrm{E}\right)$, Ilorin $\left(8.47^{\circ} \mathrm{N}, 4.59^{\circ} \mathrm{E}\right)$, Cal$\operatorname{abar}\left(4.97^{\circ} \mathrm{N}, 8.35^{\circ} \mathrm{E}\right)$, Maiduguri $\left(11.85^{\circ} \mathrm{N}, 13.06^{\circ} \mathrm{E}\right)$, Sunyani $\left(7.20^{\circ} \mathrm{N}, 2.30^{\circ} \mathrm{W}\right)$, Diapaga $\left(12.06^{\circ} \mathrm{N}, 1.75^{\circ} \mathrm{E}\right)$, Banikoara $\left(11.30^{\circ} \mathrm{N}, 2.43^{\circ} \mathrm{E}\right)$, Lokoja $\left(7.80^{\circ} \mathrm{N}, 6.73^{\circ} \mathrm{E}\right)$, Gusau $\left(12.14^{\circ} \mathrm{N}, 6.69^{\circ} \mathrm{E}\right)$, Navrongo $\left(10.90^{\circ} \mathrm{N}, 1.10^{\circ} \mathrm{W}\right)$, and Jos $\left(9.85^{\circ} \mathrm{N}, 8.89^{\circ} \mathrm{E}\right)$. Note that no data are available from the BADOPLU database for GuineaBissau, Guinea, Sierra Leone, and Liberia.

\subsection{Methodology}

We consider the Gulf of Guinea as the region covering $18^{\circ} \mathrm{W}$ to $20^{\circ} \mathrm{E}$, and $0-12.5^{\circ} \mathrm{N}$ (Fig. 1). We focus on the 2 rainy seasons of the region, defined as AMJ for the first rainy season, and SON for the second rainy season. Fig. 2 shows the mean precipitation averaged over 1981-2014 $\left(\mathrm{mm} \mathrm{d}^{-1}\right)$ for AMJ and SON. As shown in Fig. 2, the amount of precipitation increases towards the south of the region, going from about $5 \mathrm{~mm} \mathrm{~d}^{-1}$ in the north to $10 \mathrm{~mm} \mathrm{~d}^{-1}$ in the south. Higher values are observed along the coast, reaching up to $15 \mathrm{~mm} \mathrm{~d}^{-1}$ along the coasts spanning from Sierra Leone to Ivory Coast and from Nigeria to Gabon during AMJ, and from Guinea-Bissau to Liberia and from Nigeria to Gabon during SON.

Following previous studies (Sivakumar 1992, Froidurot \& Diedhiou 2017, Bichet \& Diedhiou 2018), we define a wet (dry) day using the threshold of $1 \mathrm{~mm}$ $\mathrm{d}^{-1}$. We split the wet (dry) events into 2 categories: (1) isolated wet (dry) days (or single-day events), which correspond to a single wet (dry) day preceded and followed by a dry (wet) day, and (2) wet (dry) spells, which correspond to a sequence of 2 or more consecutive wet (dry) days preceded and followed by a dry (wet) day. Hence, the duration of a wet (dry) spell, as defined in our study, spans from 2 to $91 \mathrm{~d}$. Note that unlike other studies, we do not distinguish between short and long spells, but only separate the isolated wet (dry) days from the wet (dry) spells. Following Giorgi et al. (2011), we computed the average duration of dry spells as follows:

$$
\text { DSL }=\text { NDDDS / NDS }
$$

where DSL corresponds to the average dry spell length during the season of interest, NDDDS corresponds to the total number of dry days during that season but excluding the isolated dry days, and NDS corresponds to the total number of dry spells during that season. This definition allows us to be consistent with Giorgi et al. (2011), who quantified the hydrological cycle intensity from the average dry spell length (and precipitation intensity). The identical computation is applied to wet spells. We also computed the precipitation intensity (SDII) and the total number of wet days (RR1) following the definition by the Expert Team of Climate Change Detection and Indices (ETCCDI; Zhang et al. 2011). Precipitation intensity (SDII) is computed as follows:

$$
\mathrm{SDII}=\mathrm{PP} / \mathrm{RR} 1
$$

where PP corresponds to the total amount of precipitation accumulated during the wet days $\left(>1 \mathrm{~mm} \mathrm{~d}^{-1}\right)$ of the season $\left(\mathrm{mm} \mathrm{d}^{-1}\right)$, and RR1 corresponds to the total number of wet days $\left(>1 \mathrm{~mm} \mathrm{~d}^{-1}\right.$ ) during the season. Hence, precipitation intensity (SDII) corresponds to the precipitation averaged over wet days, which implies that a change in its value directly translates into a change in the intensity of wet events, regardless of the number of wet events. The total number of dry days is directly derived from the total number of wet days (RR1). 

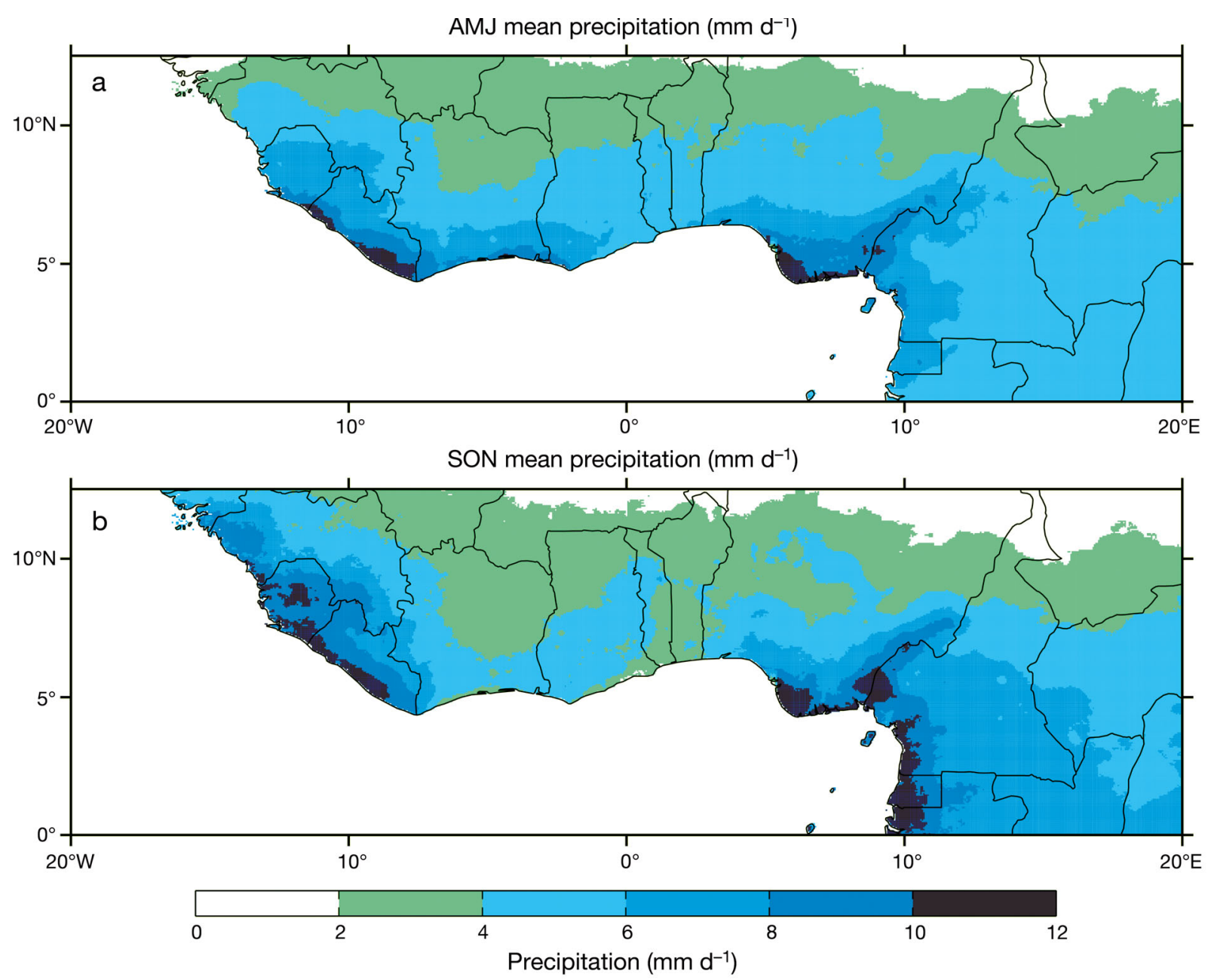

Fig. 2. (a) AMJ and (b) SON mean precipitation ( $\mathrm{mm} \mathrm{d}^{-1}$ ) averaged over 1981-2014

\section{RESULTS}

\subsection{Comparison with daily rain gauges}

Here we compare the seasonal (AMJ and SON) time series (1981-2014) for mean precipitation, number of rainy days (RR1), precipitation intensity (SDII), and average dry spell length (DSL), as computed in the 18 daily rain gauges and the 18 corresponding nearest grid-point in the CHIRPS dataset. The comparison is performed in terms of statistical distribution (quantile-quantile analyses, not shown), fit of temporal variability (Taylor diagrams; see Fig. 3 for mean precipitation only) and trend values (see Figs. 4 \& 5).

The quantile-quantile analysis for mean precipitation (not shown) indicates that in both seasons, the 2 datasets come from a very similar statistical distribution. The Taylor diagrams show that in AMJ, the CHIRPS dataset generally (1) correlates better with the rain gauges for mean precipitation (between 0.25 and 0.85 , Fig. 3a) and the number of wet days (between 0 and 0.6) than for precipitation intensity (between -0.4 and 0.6 ) and DSL (between -0.2 and 0.7 ), (2) exhibits a temporal variability that is larger than the rain gauges for mean precipitation (standard deviation [SD] between 1 and 3.5, Fig. 3a) and the number of wet days (SD between 1.5 and 3) but smaller for precipitation intensity and DSL (SD $<1$ in both cases), and (3) shows larger biases for mean precipitation (Fig. 3a) and the number of wet days (centralizer root mean squared error [CRMSE] around 2 in both cases) than for precipitation intensity and DSL (CRMSE around 1 in both cases). In SON, the CHIRPS dataset generally (1) correlates better with the rain gauges for mean precipitation (between 0.4 and 0.9, Fig. 3b) and the number of wet days (between 0.1 and 0.8 ) than for precipitation intensity and DSL (between 0 and 0.6), (2) exhibits a temporal variability that is smaller than the rain gauges for all 4 variables (SD $<1$ in all 4 cases), and (3) shows relatively low biases for all 4 variables (CRMSE $<1$ in all 4 cases). We conclude that 

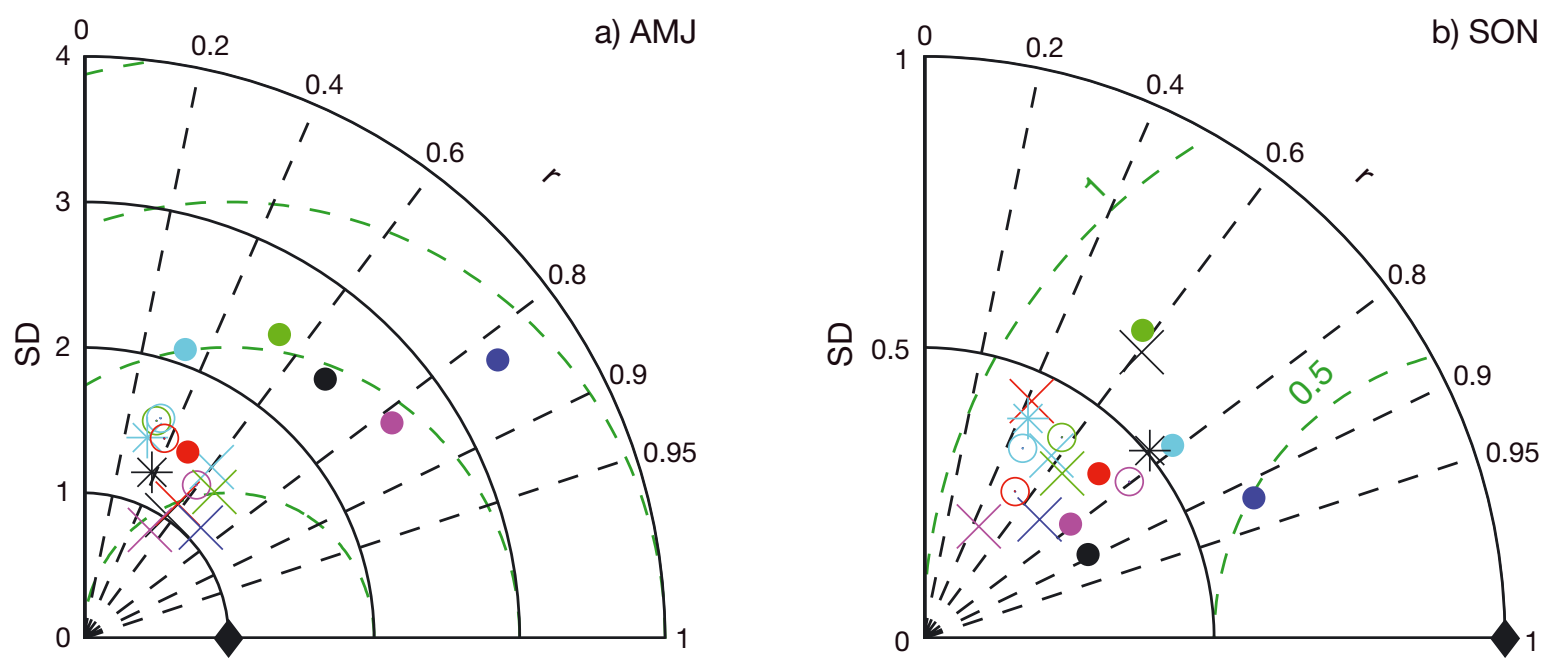

Fig. 3. Normalized Taylor diagram comparing the mean precipitation time series over 1981-2014 for (a) AMJ and (b) SON, as computed for the 18 daily rain gauge stations (black diamond) with the corresponding nearest grid point in the CHIRPS dataset (colored markers). See Fig. 4 for the interpretation of the color markers. Normalized standard deviation (SD) is on the radial axis; correlation coefficient $(\mathrm{r})$ is on the angular axis; green dashed lines indicate centralized root mean squared error (CRMSE)

for the 18 locations and 4 variables tested, the CHIRPS dataset shows results similar to the rain gauges in terms of distribution and to some extent of temporal variability. According to our results, the fit is better in SON than in AMJ, and generally better for mean precipitation and the number of wet days.

Fig. 4 shows the AMJ trends (1981-2014) for mean precipitation $\left(\mathrm{mm} \mathrm{d}^{-1}\right)$, number of rainy days $\left(\mathrm{d} \mathrm{yr}^{-1}\right)$, precipitation intensity $\left(\mathrm{mm} \mathrm{d}^{-1} \mathrm{yr}^{-1}\right)$, and DSL $\left(\mathrm{d} \mathrm{yr}^{-1}\right)$, as computed in the 18 daily rain gauges ( $x$-axis) and in the 18 corresponding nearest grid-points in the CHIRPS data (y-axis). As shown in Fig. 4a, both datasets show a positive trend in mean precipitation over 10 locations, with the CHIRPS dataset slightly underestimating the trends of the rain gauge data. In the 4 remaining locations, the CHIRPS dataset shows a negative trend and the rain gauges a positive trend. Fig. $4 \mathrm{~b}$ shows that both datasets exhibit a positive trend in the total number of wet days in 6 locations. In most of the remaining locations (except for Accra, Cotonou, and Lome), the CHIRPS dataset shows a positive trend and the rain gauges a negative trend. As shown in Fig. 4c, both datasets show a positive trend in precipitation intensity in 3 locations, and a negative trend in 2 locations. In most of the remaining locations (except for Save, Cotonou, and Lome), the CHIRPS dataset shows a negative trend and the rain gauges a positive trend. Fig. $4 \mathrm{~d}$ shows that both datasets exhibit a negative trend in DSL in 12 locations and a positive trend in 1 location. Hence, our results show that during the first rainy seasons, both datasets show a general tendency towards wetter conditions in the 18 locations tested, that is associated with an increase in the total number of wet days and shorter DSL. However, the 2 datasets strongly disagree on the sign of the trend for precipitation intensity.

Fig. 5 is identical to Fig. 4 but for SON. As shown in Fig. $5 \mathrm{a}$, both datasets show a positive trend in mean precipitation in 16 locations, with the CHIRPS dataset slightly underestimating the trends of the rain gauge data. Fig. 5b shows that both datasets exhibit a positive trend in the total number of wet days in 13 locations and a negative trend in 1 location. As shown in Fig. 5c, both datasets show a positive trend in precipitation intensity in 11 locations and a negative trend in 1 location. Fig. 5d shows that both datasets exhibit a negative trend in the average DSL in 12 locations. Hence, our results show that during the second rainy season, both datasets show a tendency towards wetter conditions in the 18 locations tested, that is associated with an increase in the total number of wet days, an increase in precipitation intensity, and shorter average DSL.

During the second rainy season, both datasets generally agree on the sign and to some extent on the magnitude of the trends of mean precipitation, precipitation intensity, total number of wet days, and DSL. During the first season, we find stronger disagreements.

\subsection{Trends in precipitation}

Fig. 6 shows the trends (1981-2014) in mean precipitation, precipitation intensity, precipitation intensity during isolated wet days, and precipitation inten- 
a) Mean precipitation trends $\left(\mathrm{mm} \mathrm{d}^{-1} \mathrm{yr}^{-1}\right)$

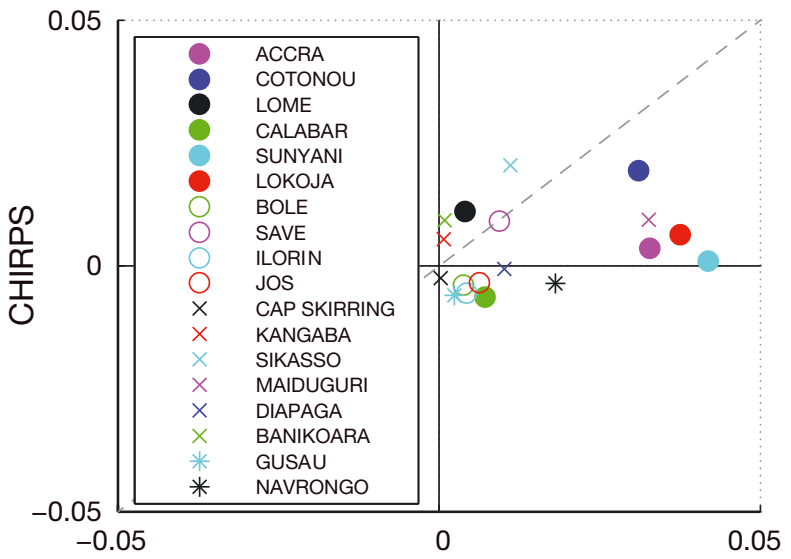

c) Precipitation intensity trends $\left(\mathrm{mm} \mathrm{d}^{-1} \mathrm{yr}^{-1}\right)$

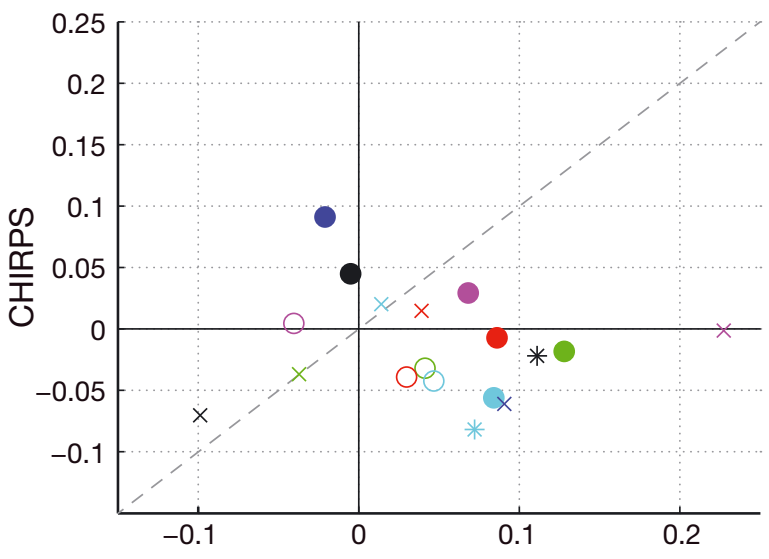

b) Number of wet days (RR1) trends $\left(\mathrm{yr}^{-1}\right)$

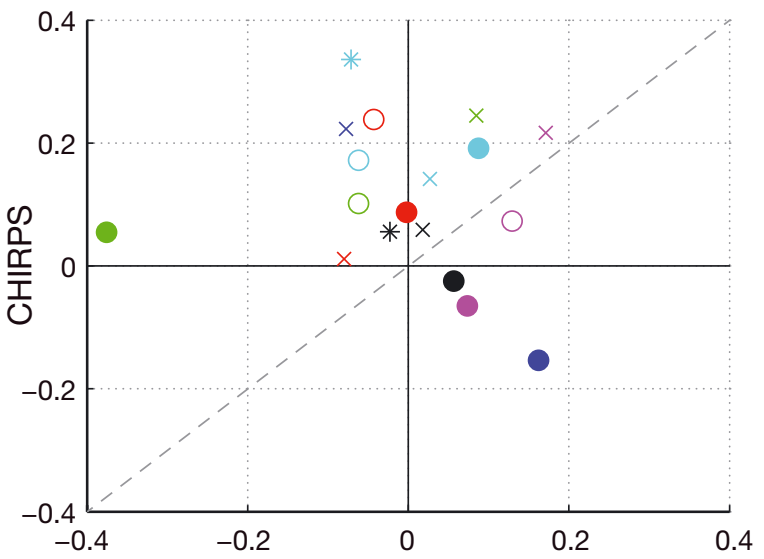

d) Average dry spell length trends $\left(\mathrm{yr}^{-1}\right)$

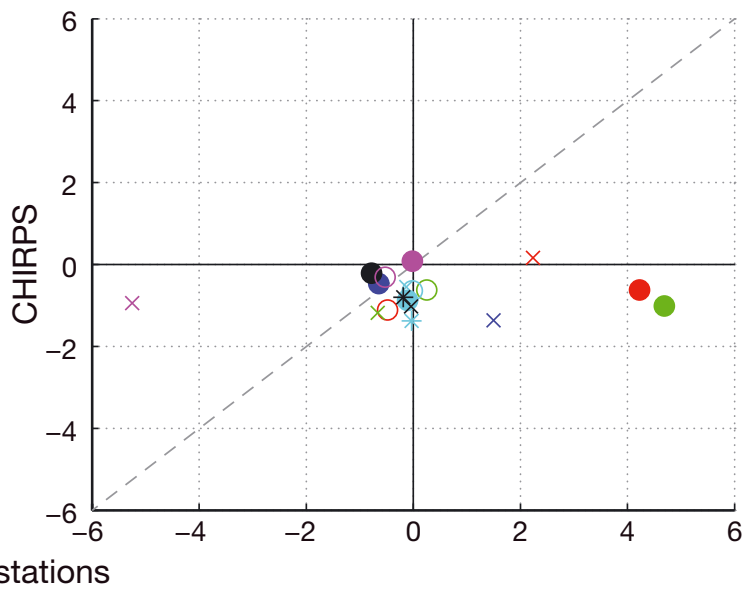

Fig. 4. Comparison of the AMJ trends (1981-2014) for (a) mean precipitation $\left(\mathrm{mm} \mathrm{d}^{-1} \mathrm{yr}^{-1}\right)$, (b) number of rainy days (d yr $\left.{ }^{-1}\right)$, (c)

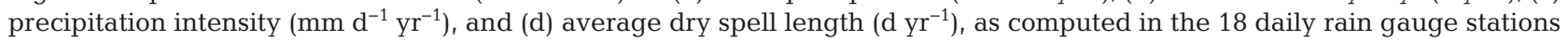
$(x$-axis) and in the corresponding nearest grid point in the CHIRPS dataset ( $y$-axis)

sity during wet spells, averaged over the first (AMJ) and second rainy season $(\mathrm{SON})$ in $\mathrm{mm} \mathrm{d}^{-1}$. During the first rainy season, only a few, small, regions show statistically significant trends in mean precipitation, of about $+1 \mathrm{~mm} \mathrm{~d}^{-1}$ (Fig. 6a). During the second rainy season, however, mean precipitation increased on average by $1.5 \mathrm{~mm} \mathrm{~d}^{-1}$ between $5^{\circ}$ and $12.5^{\circ} \mathrm{N}$, with higher trends $\left(>2 \mathrm{~mm} \mathrm{~d}^{-1}\right)$ over Liberia, Togo/Benin/ southwestern Nigeria, and the eastern Central African Republic, and decreased by about $1.5 \mathrm{~mm} \mathrm{~d}^{-1}$ over southern Cameroon/northern Gabon (Fig. 6a).

As shown in Fig. 6b, precipitation intensity during the first rainy season has increased on average by $2 \mathrm{~mm} \mathrm{~d}^{-1}$ along the coast from Togo to Gabon, and decreased on average by $2 \mathrm{~mm} \mathrm{~d}^{-1}$ between $7^{\circ}$ and $12.5^{\circ} \mathrm{N}$, with higher trends $\left(<5 \mathrm{~mm} \mathrm{~d}^{-1}\right)$ over Sierra Leone/western Guinea. During the second rainy season, precipitation intensity increased on average by
$3 \mathrm{~mm} \mathrm{~d}^{-1}$ over most of the region, with higher trends $\left(>5 \mathrm{~mm} \mathrm{~d}^{-1}\right)$ along the coasts of southern Liberia, western Ivory Coast, southern Nigeria, and western Gabon, as well as over central Togo and central Benin.

As shown in Fig. 6c, precipitation intensity during isolated wet days has decreased by more than $5 \mathrm{~mm}$ $\mathrm{d}^{-1}$ over Sierra Leone/western Guinea, and increased by more than $5 \mathrm{~mm} \mathrm{~d}^{-1}$ along the coast from Togo to Gabon. During the second rainy season, precipitation intensity during isolated wet days has increased by more than $5 \mathrm{~mm} \mathrm{~d}^{-1}$ over most of the region. For both seasons, the trends in precipitation intensity during wet spells (Fig. 6d) are similar to the trends in precipitation intensity (Fig. 6b).

Therefore, the CHIRPS dataset shows different trends in mean precipitation for the 2 rainy seasons. During the first season, the lack of significant trend in mean precipitation hides a strong increase (de- 

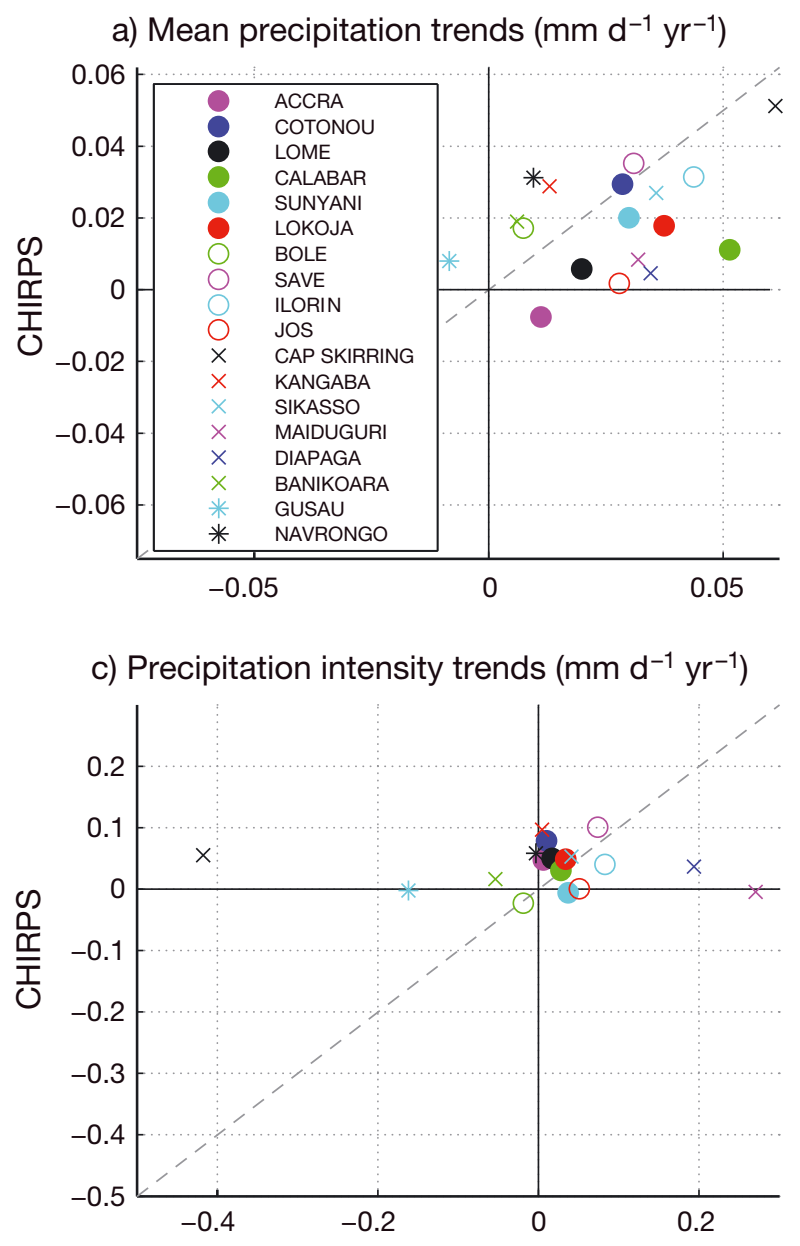
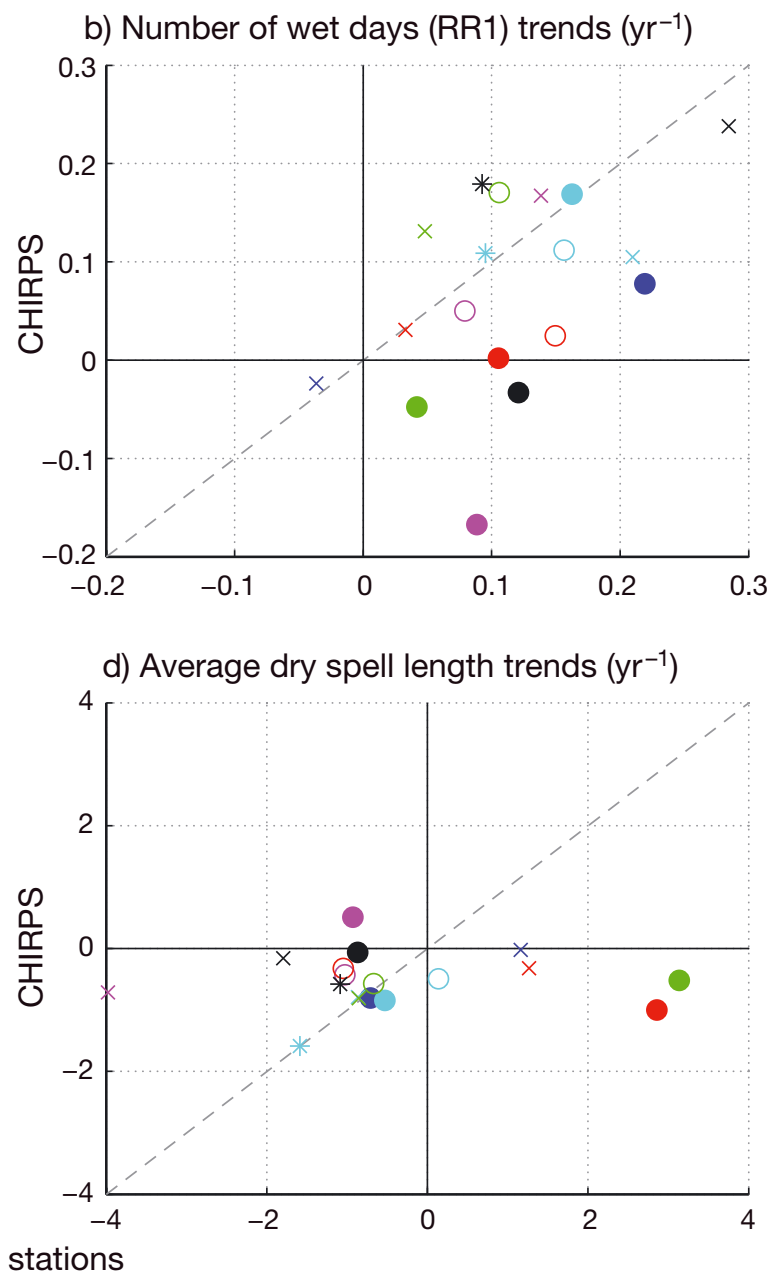

Fig. 5. Identical to Fig. 4 but for SON

crease) in precipitation intensity during isolated wet days (wet spells), all along the coast from Togo to Gabon (between $7^{\circ}$ and $12.5^{\circ} \mathrm{N}$ ). During the second season, the clear increase in mean precipitation between $5^{\circ}$ and $12.5^{\circ} \mathrm{N}$ results at least partly from a strong increase in precipitation intensity during isolated wet days. Note that in both seasons, precipitation intensity has increased along the coast, in particular during isolated wet days. To understand the additional processes involved, the next section investigates the trends in the distribution of wet and dry events since 1981.

\subsection{Trends in the distribution of wet and dry events}

Fig. 7 shows the trends in AMJ and SON over the period 1981-2014 in the total number of wet days, the number of isolated wet days, the number of wet spells, and the average length of wet spells in percentage of change relative to the average length of wet spells over the season. During the 2 rainy seasons, the total number of wet days decreased on average by $15 \mathrm{~d}$ along the coast from Cameroon to Gabon, and increased on average by $10 \mathrm{~d}$ between $7^{\circ}$ and $12.5^{\circ} \mathrm{N}$ (Fig. 7a). The number of isolated wet days increased on average by $5 \mathrm{~d}$ over most of the region (Fig. 7b), the number of wet spells increased on average by 4 between $5^{\circ}$ and $12.5^{\circ} \mathrm{N}$ (Fig. $7 \mathrm{C}$ ), and the average length of wet spells decreased on average by $40 \%$ over most the region, with higher trends $(<50 \%)$ along the coast from Ghana to Gabon in AMJ and from Nigeria to Gabon in SON (Fig. 7d).

Hence, the CHIRPS data show similar trends in the distribution of wet events in the 2 seasons. The total number of wet days has increased north of $7^{\circ} \mathrm{N}$ due to more numerous wet spells, and decreased south of $5^{\circ} \mathrm{N}$ (along the coast) due to a strong shortening of wet spells (in favor of isolated wet days). 


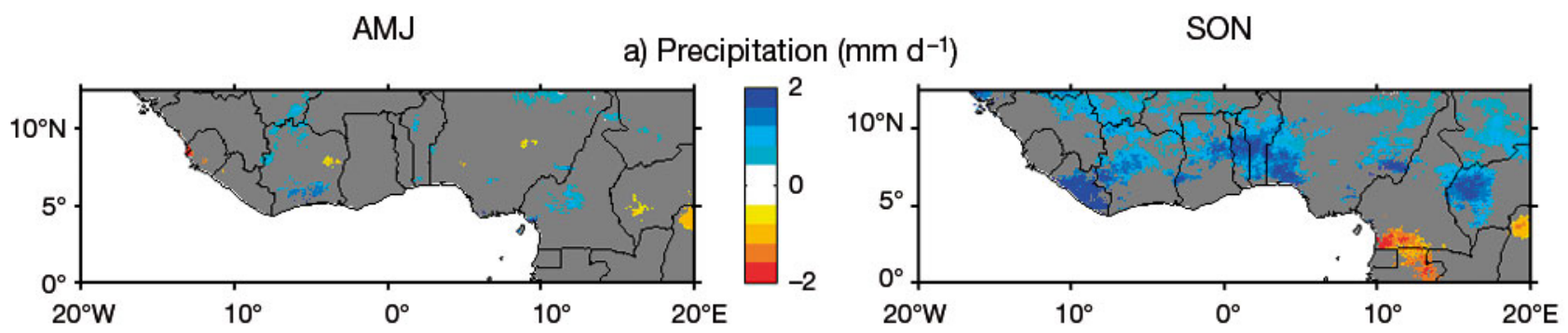

b) Precipitation intensity $\left(\mathrm{mm} \mathrm{d}^{-1}\right)$
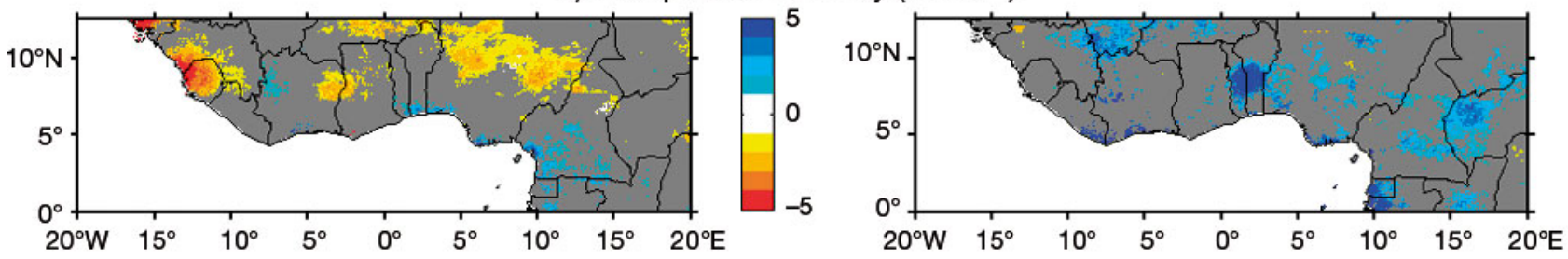

c) Precipitation intensity during isolated wet days $\left(\mathrm{mm} \mathrm{d}^{-1}\right)$
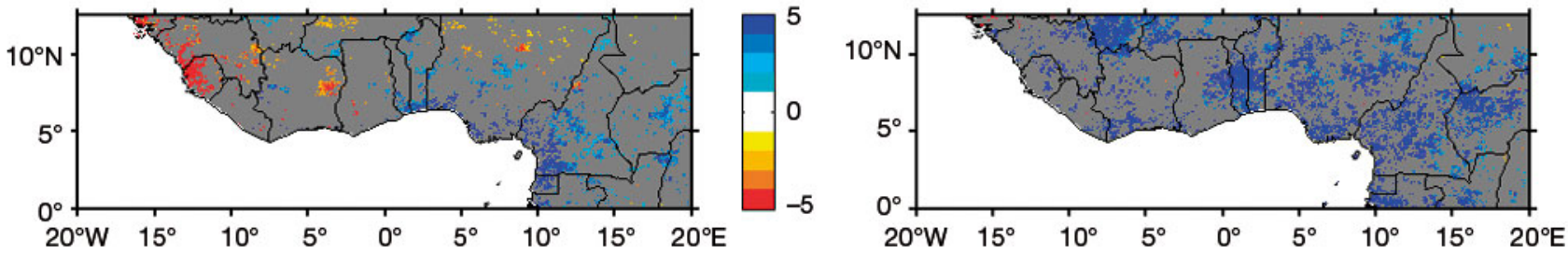

d) Precipitation intensity during wet spells $\left(\mathrm{mm} \mathrm{d}^{-1}\right)$
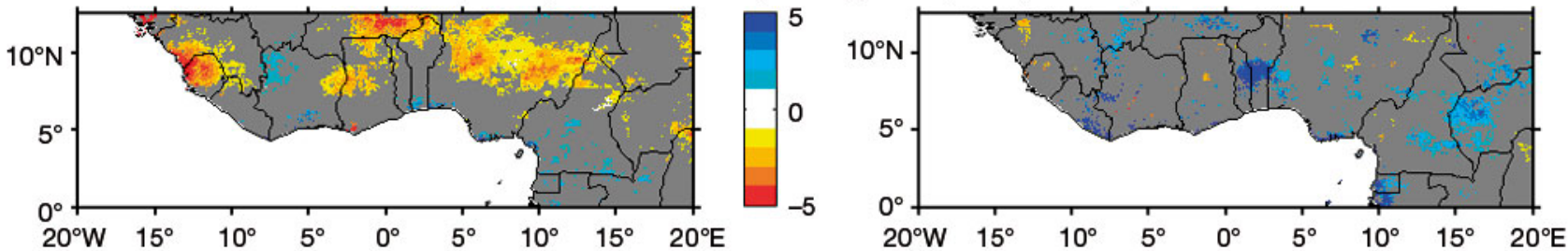

Fig. 6. Trend maps (1981-2014) for (a) precipitation, (b) precipitation intensity, (c) precipitation intensity during isolated wet days, and (d) precipitation intensity during wet spells, as averaged over AMJ and SON, in mm $\mathrm{d}^{-1}$ since 1981 . Trends that are not significant according to Student's $t$-test at $95 \%$ are shaded in gray

Fig. 8 is identical to Fig. 7 but for dry events. During the 2 seasons, the total number of dry days increased on average by $15 \mathrm{~d}$ along the coast from Cameroon to Gabon, and decreased on average by $10 \mathrm{~d}$ between $7^{\circ}$ and $12.5^{\circ} \mathrm{N}$ (Fig. 8a). The number of isolated dry days increased on average by $5 \mathrm{~d}$ over the entire region (Fig. 8b), and the number of dry spells increased on average by 4 over most of the region (Fig. 8c), and the average length of dry spells decreased on average by $30 \%$ over most of the region, with higher trends $(<50 \%)$ over the northern part of the region (Fig. 8d). Hence, the CHIRPS data show similar trends in the distribution of dry events for the 2 seasons. The total number of dry days has increased along the coast due to more numerous isolated dry days and more numerous dry spells, and decreased north of $7^{\circ} \mathrm{N}$ due to a strong shortening of dry spells (in favor of isolated wet days).

\section{DISCUSSION AND CONCLUSION}

To summarize, our study shows that during the second rainy season, the CHIRPS dataset generally agrees with a selection of 18 rain gauges, both in the sign and to some extent in the magnitude of the trends in mean precipitation, number of wet days, precipitation intensity, and average DSL. Stronger disagreements are observed during the first season, in particular for precipitation intensity. Note that no data are available from the BADOPLU database for Sierra Leone and Guinea, where the CHIRPS dataset shows the strongest decrease in precipitation intensity. In addition, the comparison of the corresponding time series between the 2 datasets indicates that the distribution, and to some extent the temporal variability, of the 2 datasets agree in both seasons, generally showing a better fit for (1) mean precipitation 


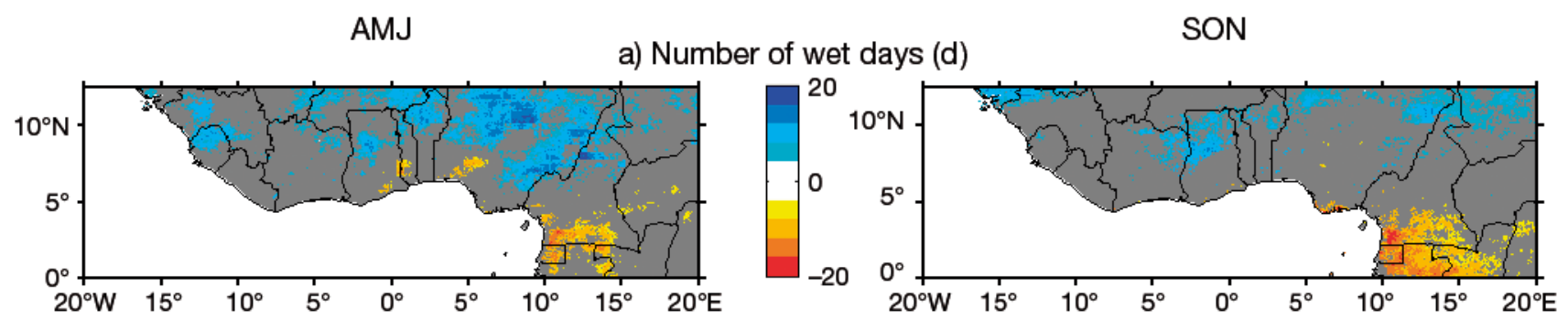

b) Number of isolated wet days (d)

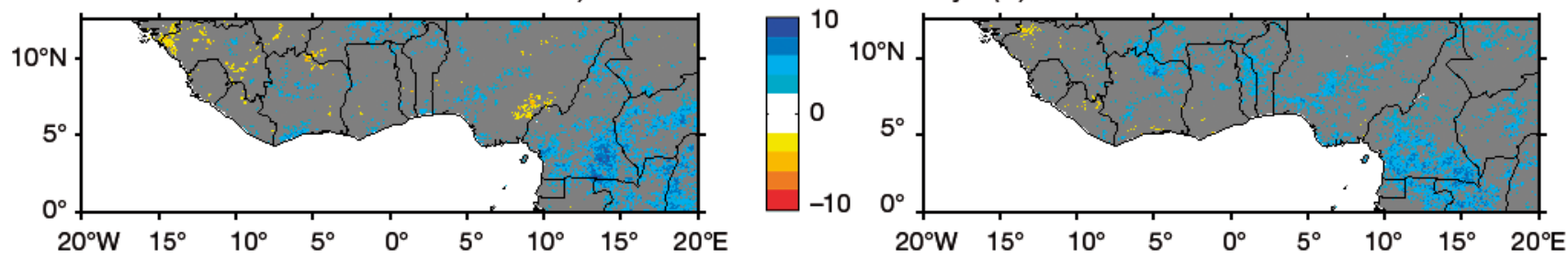

c) Number of wet spells
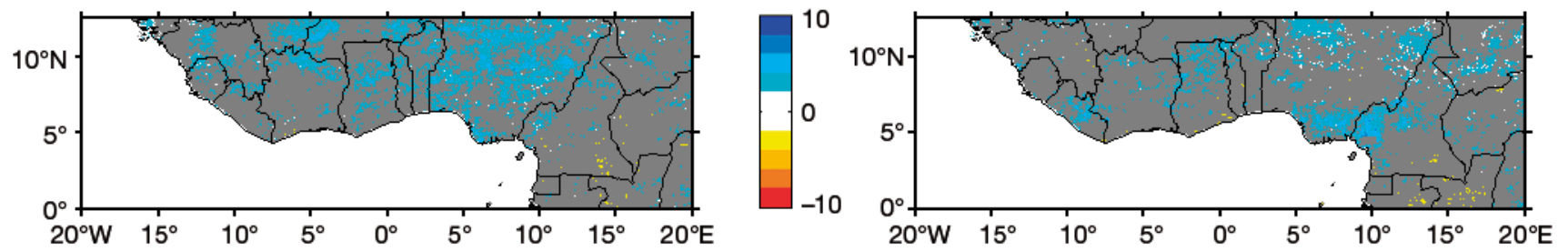

d) Average length of wet spells (\%)
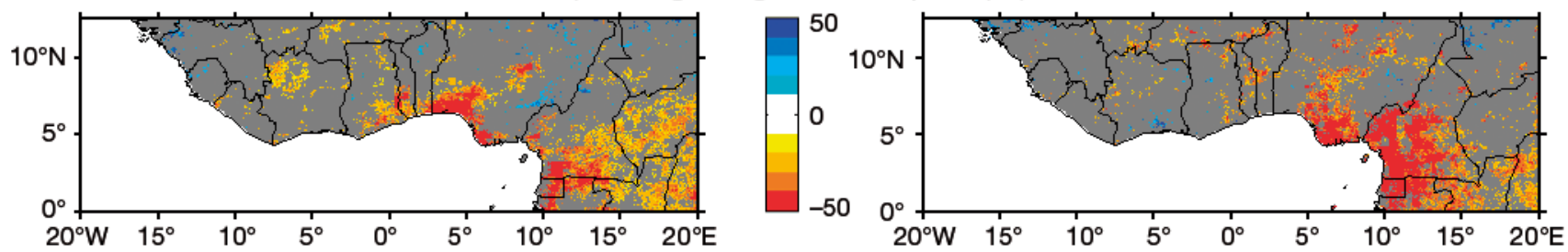

Fig. 7. Trend maps (1981-2014) for (a) total number of wet days, (b) total number of isolated wet days, (c) total number of wet spells, and (d) average length of wet spells (\%), for AMJ and SON. Trends that are not significant according to Student's $t$-test at $95 \%$ are shaded in gray

and the number of wet days and (2) the second rainy season (SON). Hence, despite a few biases, our evaluation indicates good confidence in the use of the CHIRPS data for our study.

Over the past $35 \mathrm{yr}$, we find that the CHIRPS dataset depicts different trends in mean precipitation for the 2 rainy seasons. In agreement with other observational datasets (Maidment et al. 2015, Sanogo et al. 2015, Sylla et al. 2016), we find a clear precipitation increase during the second rainy season (between $5^{\circ}$ and $10^{\circ} \mathrm{N}$ ) that is not observed during the first season. We also find that the CHIRPS dataset shows a strong reorganization of rainfall, that is different for the 2 seasons (especially for precipitation intensity) and not spatially homogeneous (north/south).

During the first rainy season, we find that the lack of significant trend in mean precipitation hides a strong trend towards less frequent but more intense rainfall (shorter but stronger rainfall events) along the coast, which is expected to increase the likelihood of flooding and droughts in this region. This result is in good agreement with the high occurrence of devastating floods along the coast in the recent years (OCHA and EM-DAT). Opposite trends are found over the northern part of the region. During the second rainy season, we find, in agreement with Sanogo et al. (2015), that the clear increase in mean precipitation observed between $5^{\circ}$ and $12.5^{\circ} \mathrm{N}$ results from more intense (in particular during isolated wet days) and more frequent precipitation, overall increasing the likelihood for flooding. Over southern Cameroon/ northern Gabon, the trend towards more intense and less frequent rainfall is expected to increase the likelihood for floods and droughts.

In such circumstances, and in the light of poor documentation on this issue, our results raise the need 


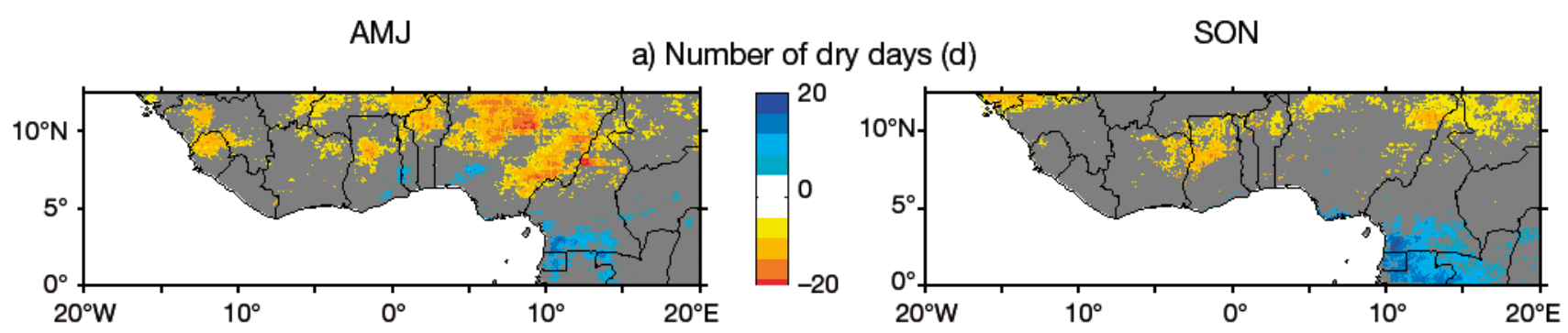

b) Number of isolated dry days (d)
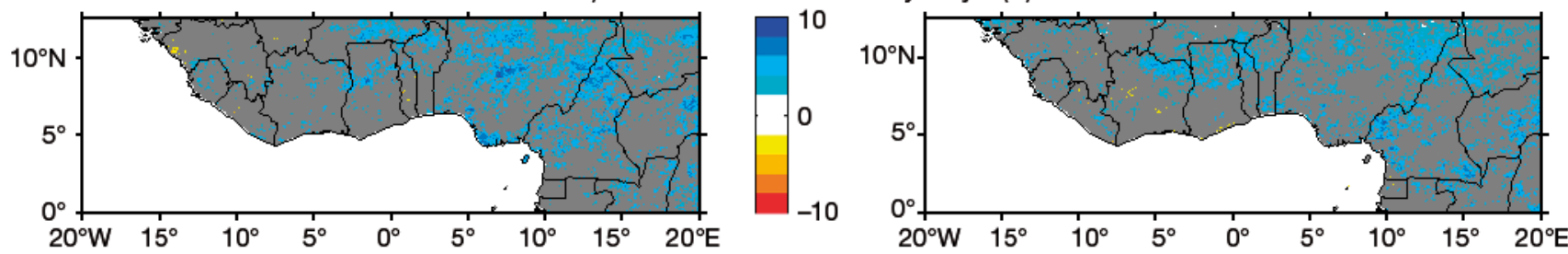

c) Number of dry spells
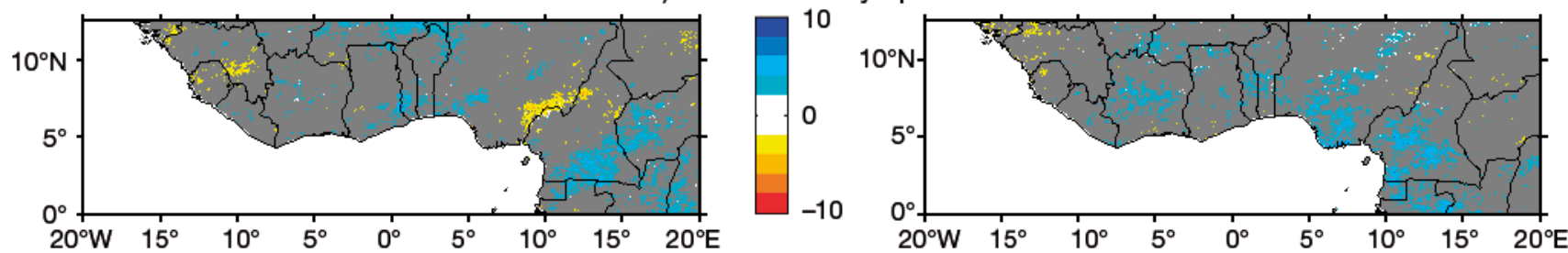

d) Average length of dry spells (\%)
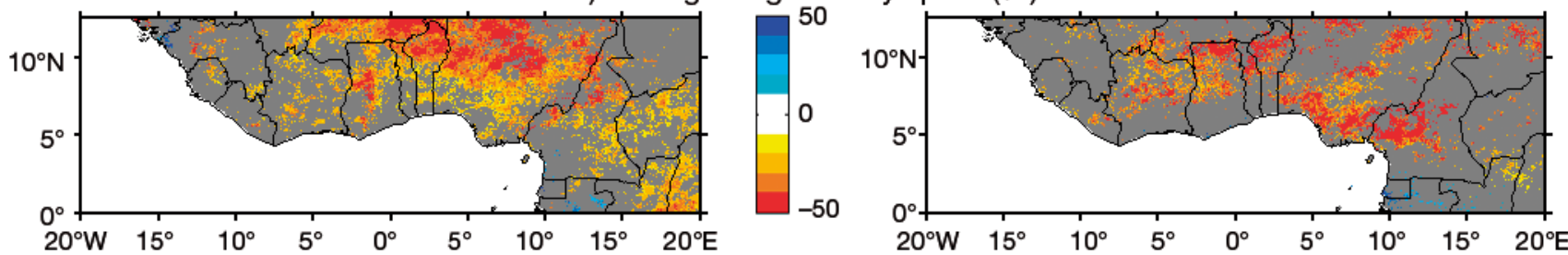

Fig. 8. Identical to Fig. 7, but for dry days

for a more in-depth investigation of the recent trends in the Gulf of Guinea. The biases found across the 2 observational datasets used in our study also raise the need for a more comprehensive comparison of such trends across the different observational products available for daily precipitation in this region, as well as the need for the acquisition of new data in countries where such data are currently missing, such as Liberia, Sierra Leone, Guinea, and GuineaBissau.

Furthermore, the mechanisms behind these trends should also be investigated in order to better apprehend the future evolution of these trends and better anticipate their implications for society. Although the exploration of such mechanisms is beyond the scope of this study, our results suggest that they may be different in the 2 seasons. As previously mentioned, precipitation in this region is governed by the West African Monsoon. However, it has been shown (Le- bel et al. 2003) that the 2 rainy seasons belong to different phases of the monsoon, being 'oceanic' from April to June, and 'continental' from July to November. Therefore, whereas the changes in AMJ rainfall can be linked to changes in the Atlantic sea surface temperatures (e.g. Nguyen et al. 2011, Nnamchi \& Li 2016), the changes in SON rainfall can be linked to land changes, and may even be related to the preceding summer monsoon over the Sahel (e.g. Bichet \& Diedhiou 2018). According to Sanogo et al. (2015), the SON 'rainfall recovery' over the Gulf of Guinea can even be considered as a reminiscence of the Sahel recovery during the summer months, thereby including potential drivers such as changes in Saharan temperatures (Taylor et al. 2012). Finally, an additional possible driver for these trends includes the potential intensification of the hydrological cycle that is expected to result from global warming (e.g. Allen \& Ingram 2002, Giorgi et al. 2011). 
Acknowledgements. The research leading to this publication has received funding from the NERC/DFID 'Future Climate for Africa' program under the AMMA-2050 project, grant number NE/M019969/1. We acknowledge the Climate Hazards Group for CHIRPS data (http://chg.geog.ucsb.edu/data/ chirps). Our research has benefited from the access to rainfall data sets provided by the AMMA-CATCH observatory, the AMMA international program, DMN Burkina, ANACIM, and DMN Niger; we greatly thank all of them, as well as the people at the IGE computation center (Guillaume Quantin, Véronique Chaffard, Patrick Juen, and Wajdi Nechba) for their technical support, and Geremy Panthou for his role in accessing the data and insights into the dataset.

\section{LITERATURE CITED}

Allen MR, Ingram WJ (2002) Constraints on future changes in climate and the hydrologic cycle. Nature 419:224-232

Bichet A, Diedhiou A (2018) West African Sahel has become wetter during the last 30 years, but dry spells are shorter and more frequent. Clim Res 75:155-162

Christensen JH, Hewitson B, Busuioc A, Chen A and others (2007) Regional climate projections. In: Solomon S, Qin D, Manning M, Chen Z and others (eds) Contribution of Working Group I to the Fourth Assessment Report of the Intergovernmental Panel on Climate Change. Cambridge University Press, Cambridge, p 847-940

Diallo I, Sylla MB, Camara M, Gaye AT (2013) Interannual variability of rainfall over the Sahel based on multiple regional climate models simulations. Theor Appl Climatol 113:351-362

Diatta S, Fink AH (2014) Statistical relationship between remote climate indices and West African monsoon variability. Int J Climatol 34:3348-3367

Froidurot S, Diedhiou A (2017) Characteristics of wet and dry spells in the West African monsoon system. Atmos Sci Lett 18:125-131

Funk C, Peterson P, Landsfeld M, Pedreros D and others (2015) The climate hazards infrared precipitation with stations - a new environmental record for monitoring extremes. Sci Data 2:150066

Giorgi F, Im ES, Coppola E (2011) Higher hydroclimatic intensity with global warming. J Clim 24:5309-5324

Kannak L, Knippertz P, Fink AH, Kniffka A, Pante G (2017) Why do global climate models struggle to represent lowlevel clouds in the West African summer monsoon? J Clim 30:1665-1687

Klutse NAB, Sylla MB, Diallo I, Sarr A and others (2016) Daily characteristics of West African summer monsoon precipitation in CORDEX simulations. Theor Appl Climatol 123:369-386

Lebel T, Diedhiou A, Laurent H (2003) Seasonal cycle and

Editorial responsibility: Filippo Giorgi,

Trieste, Italy interannual variability of the Sahelian rainfall at hydrological scales. J Geophys Res 108:8389

*Maidment RI, Allan RP, Black E (2015) Recent observed and simulated changes in precipitation over Africa. Geophys Res Lett 42:8155-8164

Nguyen H, Thorncroft CD, Zhang C (2011) Guinean coastal rainfall of the West African Monsoon. Q J R Meteorol Soc 137:1828-1840

Nicholson SE (2000) The nature of rainfall variability over Africa on time scales of decades to millenia. Global Planet Change 26:137-158

Nnamchi HC, Li J (2016) Floods and droughts along the Guinea Coast in connection with the South Atlantic Dipole. In: Li J, Swinbank R, Grotjahn R, Volkert H (eds) Dynamics and predictability of large-scale, high-impact weather and climate events. Cambridge University Press, Cambridge, p 271-279

Ofori-Sarpong E, Annor J (2001) Rainfall over Accra, 190190. Weather 56:55-62

* Panthou G, Vischel T, Lebel T, Blanchet J, Quantin G, Ali A (2012) Extreme rainfall in West Africa: a regional modeling. Water Resour Res 48:W08501

* Panthou G, Lebel T, Vischel T, Quantin G and others (2018) Rainfall intensification in tropical semi-arid regions: the Sahelian case. Environ Res Lett 13:064013

Redelsperger JL, Thorncroft CD, Diedhiou A, Lebel T, Parker DJ, Polcher J (2006) African Monsoon Multidisciplinary Analysis (AMMA): an international research project and field campaign. Bull Am Meteorol Soc 87:1739-1746

Koux F (1988) The West African squall line observed on 23 June 1981 during COPT 81: kinematics and thermodynamics of the convective region. J Atmos Sci 45:406-426

Sanogo S, Fink AH, Omotosho JA, Ba A, Redl R, Ermert V (2015) Spatio-temporal characteristics of the recent rainfall recovery in West Africa. Int J Climatol 35:4589-4605

Sivakumar MVK (1992) Empirical analysis of dry spells for agricultural applications in West Africa. J Clim 5:532-539

Sommeria G, Testud J (1984) COPT 81: a field experiment designed for the study of dynamics and electrical activity of deep convection in continental tropical regions. Bull Am Meteorol Soc 65:4-10

Sylla MB, Nikiema PM, Gibba P, Kebe I, Klutse NAB (2016) Climate change over West Africa: recent trends and future projections. In: Yaro JA, Hesselberg J (eds) Adaptation to climate change and variability in rural West Africa. Springer International Publishing, Basel, p 25-40

Taylor CM, Belušić D, Guichard F, Parker DJ and others (2017) Frequency of extreme Sahelian storms tripled since 1982 in satellite observations. Nature 544:475-478

* Zhang X, Alexander L, Hegerl GC, Jones P and others (2011) Indices for monitoring changes in extremes based on daily temperature and precipitation data. Wiley Interdiscip Rev Clim Change 2:851-870

Submitted: April 17, 2018; Accepted: September 3, 2018 Proofs received from author(s): October 9, 2018 